\title{
Violência contra crianças: informe mundial
}

\author{
Violence against children: a global report
}

Paulo Sérgio Pinheiro ${ }^{1}$

\footnotetext{
${ }^{1}$ Watson Institute, Brown University, USA. www.violencesutdy.org. pinheiro@sgsvac.org
}

\begin{abstract}
In 2003 I was appointed by the UN Secretary-General as his Independent Expert to conduct a study with the support of the Office of the High Commissioner for Human Rights (OHCHR), UNICEF and WHO. The study will provide an in-depth global picture of violence against children and propose clear recommendations for the improvement of legislation, policy and programmes relating to the prevention of and responses to violence against children. The study will document the magnitude, incidence and consequences of various types of violence against children.
\end{abstract}

Key words Human rights and health, Violence against children, Violence and health
Resumo Em 2003 fui apontado pelo secretáriogeral da ONU como um especialista independente para conduzir um estudo de apoio ao gabinete do Alto Comissariado para os Direitos Humanos (OHCHR), Unicefe OMS. O estudo apresenta um profundo e amplo panorama da violencia contra as crianças e propõe recomendações muito contundentes para melhorar a legislação, a política e os programas relacionados à prevenção e às respostas ao problema. O estudo documenta a magnitude, a incidência e as conseqüências dos vários tipos de violência contra as crianças.

Palavras-chave Direitos humanos e saúde, Violência contra as crianças, Violência e saúde 


\section{Escopo do estudo}

O estudo será direcionado pelos tratados em direitos humanos internacionais, em especial a Convenção sobre os Direitos da Criança e a jurisprudência do seu comitê e outros corpos de tratados sobre direitos humanos. O foco do estudo será nas crianças como vítimas da violência, embora alguma atenção seja dedicada a crianças como praticantes de violência contra outras crianças. Também será considerado o papel dos homens e dos meninos como defensores da violência e agentes da mudança.

O conceito de violência tratado na Convenção sobre os Direitos da Criança, em especial nos artigos 19, 34 e 37, em outros tratados e instrumentos referentes a direitos humanos, como a Declaração de Eliminação da Violência Contra as Mulheres de 1993, também fundamentará o estudo. De acordo com o artigo 19 da Convenção e o trabalho do Comitê sobre os Direitos da Criança, violência, para os propósitos do estudo, compreenderá todas as formas de violência física ou mental, ferimento e abuso, negligência ou tratamento negligente, maustratos ou exploração, inclusive abuso sexual. O estudo também será calcado na definição geral de abuso infantil acordada pelos especialistas que participaram da Consulta sobre Prevenção do Abuso Infantil da OMS de 1999. Segundo essa definição, abuso ou mau-trato infantil constitui toda forma de mautrato físico e/ou psicológico, abuso sexual ou tratamento negligente ou comercial ou outra forma de exploração que cause ou possa causar dano à saúde da criança, à sua sobrevivência ou dignidade no contexto de uma relação de responsabilidade, confiança ou poder.

O estudo tentará fornecer uma compreensão da natureza, extensão, causas e conseqüências das diferentes formas de violência contra as crianças, levando em consideração os vários ambientes em que a violência se dá. Dará atenção especial à violência contra a criança na família, adotando uma abordagem ampla e abrangente. Também serão considerados outros ambientes, públicos e privados, onde ocorre a violência contra a criança: escolas, inclusive escolas militares; instituições religiosas; instituições de cuidado, como orfanatos e casas de acolhida; instituições de detenção e prisões; nos esportes; nas ruas e em situações de trabalho. Será abordada a violência no contexto da administração da justiça, com ênfase no uso da pena capital e castigo físico, bem como mau-trato e tortura. Serão abordadas as causas e as consequiências da violência contra as crianças, e serão explorados os sistemas, estruturas e realidades sociais subjacentes à violência e seus vínculos com a pobreza e a globalização. Os custos da violência contra as crianças para a sociedade, inclusive a perpetuação do ciclo de violência, também serão considerados.

\section{A preparação do estudo}

Em fevereiro de 2005, apresentei um relatório na 61 a sessão da Assembléia Geral das Nações Unidas referente à preparação do estudo do secretáriogeral sobre violência contra as crianças. Desde a submissão do relatório de progresso do estudo na $61^{\text {a }}$ sessão da Comissão de Direitos Humanos, o especialista independente continuou recolhendo informações a fim de fornecer um panorama global detalhado da violência contra as crianças, documentando a sua natureza, incidência, causas e conseqüências, levando em consideração os diversos ambientes nos quais se dá tal violência, priorizando a coleta de informações sobre as melhores práticas de prevenção e resposta, inclusive as desenvolvidas a partir de contribuições das crianças.

Uma série de processos foi iniciada pelo especialista independente como parte de uma estratégia multifacetada, a fim de mobilizar apoio global para o estudo e seu objetivo de erradicar a violência contra as crianças, bem como coletar informações, que serão apresentadas no relatório final do estudo - uma publicação abrangente com os achados do estudo e uma versão do estudo adaptada para as crianças. Os processos incluíram a submissão de um questionário a governos e um apelo para contribuições públicas. O especialista independente incentivou a organização de consultas regionais, sub-regionais e nacionais, bem como reuniões com especialistas temáticos sobre determinadas questões e temas relacionados à violência contra as crianças, e realizou uma série de visitas de campo em diversos países. Também solicitou uma análise das observações conclusivas do Comitê sobre os Direitos da Criança e dos relatórios de mandatários de procedimentos especiais relevantes da Comissão de Direitos Humanos, a fim de determinar se foram discernidas quaisquer tendências a respeito da violência contra as crianças por esses mecanismos. O especialista independente continuou presidindo o conselho editorial de especialistas e incentivou a criação de pesquisas e outras redes. No decorrer do trabalho, o especialista independente enfatizou a importância da participação das crianças e insistiu para que as crianças participassem de todos os processos relacionados ao estudo. 


\section{Questionário aos governos}

Em março de 2004, o especialista independente distribuiu para os governos um questionário sobre a questão da violência contra as crianças, incentivando-os a fornecer exemplos de boas práticas e abordagens inovadoras e a esboçar os obstáculos encontrados ao tratar de todas as formas de violência contra as crianças. Em vários países, a preparação das respostas ao questionário ofereceu a primeira oportunidade para que os governos tivessem um quadro claro do problema da violência contra as crianças, da legislação, políticas e programas desenvolvidos nessa área. Em muitos casos, a preparação das respostas gerou um debate nacional acerca da questão da violência contra as crianças e inspirou ações para tratar do problema. Diversos Estados desenvolveram mecanismos para coordenar a preparação das respostas, que incluíram a organização de encontros intersetoriais regulares, compreendendo diferentes autoridades governamentais, inclusive em níveis federal, estadual, provincial e municipal, bem como ONGs, instituições nacionais de direitos humanos e outras partes da sociedade civil, inclusive crianças.

Até 16 de agosto de 2005, o especialista independente havia recebido 117 respostas: 28 do Grupo de Estados Africanos, 26 do Grupo Asiático, 19 do Grupo da Europa Oriental, 24 do Grupo da América Latina, 20 do Grupo da Europa Ocidental e outros Estados e uma dos Territórios Palestinos Ocupados. Todas as respostas estão no site do Escritório do Alto Comissariado da ONU para Direitos Humanos, http://www.ohchr.org/english/bodies/crc/study.htm.

\section{Consultas regionais}

O especialista independente participou de nove consultas regionais sobre o estudo, realizadas entre março e julho de 2005: Consulta Regional do Caribe, realizada em Trinidad e Tobago, de 10 a 11 de março de 2005; Consulta Regional do Sul da Ásia, realizada no Paquistão, de 17 a 20 de maio de 2005; Consulta Regional da África Ocidental e Central, realizada no Mali, de 23 a 25 de maio de 2005; Consulta Regional da América Latina, realizada na Argentina, de 30 de maio a $1^{\circ}$ de junho de 2005; Consulta Regional da América do Norte, realizada no Canadá, de 2 a 3 de junho de 2005; Consulta Regional do Leste da Ásia e Pacífico, realizada na Tailândia, de 14 a 16 de junho de 2005; Consulta Regional do Oriente Médio e Norte da África, realizada no Egito, de 27 a 29 de junho de 2005; Consulta
Regional da Europa e Ásia Central, realizada na Eslovênia, de 5 a 7 de julho de 2005; e Consulta Regional do Leste e Sul da África, realizada na África do Sul, de 18 a 20 de julho de 2005. O especialista independente gostaria de agradecer a importante contribuição dos escritórios do Unicef em diferentes partes do mundo, facilitando as consultas regionais e apoiando os processos preparatórios e de acompanhamento em nível de país. Deseja enfatizar que as consultas geraram informações fundamentais para o estudo e também dedicaram atenção crescente ao problema da violência contra as crianças, oferecendo uma oportunidade de mobilização da vontade política para tratar do assunto. As consultas também promoveram a conscientização da sociedade civil e outros interessados, fortaleceram parcerias e redes envolvidas com o problema da violência contra as crianças e promoveram o diálogo entre governos e outros participantes.

Cada uma das consultas regionais reuniu, em média, 350 participantes, inclusive representantes e parlamentares do governo, representantes das entidades da ONU, organizações regionais e intergovernamentais, ONGs, instituições nacionais de direitos humanos e outras partes da sociedade civil, a mídia, organizações religiosas, bem como as crianças, e ofereceu um fórum no qual puderam ser reunidas informações sobre a violência contra as crianças e os passos à prevenção e respostas ao problema. As preparações para cada consulta foram dirigidas por comitês gerais de trabalhos regionais e grupos de coordenação, compostos de representantes do governo, entidades da ONU e outras entidades internacionais, ONGs e outras partes da sociedade civil, tendo o Unicef como facilitador, com o apoio do Escritório do Alto Comissariado da ONU para Direitos Humanos, OMS e outros parceiros. Em consulta com o especialista independente, a Rede de Informação sobre os Direitos da Criança (CRIN) ofereceu resumos diários das consultas regionais (www.crin.org e www.violencestudy.org). A CRIN também desenvolveu páginas interativas no seu site para as crianças e jovens.

Cada consulta regional resultou em um documento final que descreveu o processo de planejamento, pontos altos do evento, melhores práticas para a prevenção e resposta à violência, e principais recomendações para ação futura. Os participantes de várias consultas concordaram em redigir uma declaração da consulta que, embora tratasse do seu contexto em particular, enfatizasse a importância da prevenção da violência contra as crianças e a necessidade de mecanismos de acompanhamento das consultas e do estudo. 
Na consulta regional do Sul da Ásia, foi criado o Fórum do Sul da Ásia para o Fim da Violência contra as Crianças para facilitar reuniões regulares dos governos na região com o objetivo de acompanhar as recomendações relacionadas ao estudo, solicitando o apoio do Grupo de Coordenação do Sul da Ásia contra o Tráfico de Mulheres e Crianças para Fins de Exploração Sexual Comercial no Sul da Ásia e a Associação do Sul da Ásia para Cooperação Regional (SAARC). Na consulta regional, cada governo apresentou as principais preocupações, como a violência contra meninas, trabalho infantil, crianças de rua, tráfico, violência nas escolas e a influência de conflitos, e foi apresentada uma gama de respostas. Por exemplo, o governo da Índia informou acerca da criação de uma Comissão Nacional para as Crianças, cujo foco é a proteção infantil; o Paquistão criou centros nacionais de proteção infantil para a proteção das crianças.

A frase conclusiva da consulta do Leste da Ásia e Pacífico destacou a crescente vulnerabilidade das crianças pegas na fronteira migrando e a importância de capacitar profissionais-chave para trabalhar com crianças, tais como assistentes sociais, professores, profissionais legais e médicos, bem como grupos comunitários, inclusive organizações baseadas na fé. As recomendações do encontro do Leste da Ásia e Pacífico serão levadas para a Oitava Consulta Ministerial do Leste da Âsia e Pacífico no início de 2007.

Na consulta do Oriente Médio e Norte da África, uma discussão aberta sobre a questão da violência contra as crianças se deu entre as crianças, autoridades do governo, membros da sociedade civil e outros especialistas que participavam da consulta. Foi adotada uma declaração pelos delegados, enfatizando a necessidade de fortalecer as instituições, famílias e comunidades para evitar a violência contra as crianças. A declaração conclamava os participantes a se comprometerem a incluir a "violência contra as crianças" como um item permanente da agenda da Liga Árabe, da União Africana e das cúpulas da Organização de Conferência Islâmica. No último dia, outra helpline infantil foi criada na região pela primeira dama do Egito. A helpline foi apoiada por uma campanha de conscientização sobre a violência contra as crianças e a linha de discagem gratuita recebeu 15.000 ligações de crianças nos primeiros doze dias de funcionamento.

As conclusões finais das nove áreas prioritárias relativas à violência contra as crianças foram adotadas na consulta regional da Europa e Ásia Central. As discussões durante a consulta se concentraram na violência contra as crianças em diferentes tipos de instituições residenciais, nas quais são colocadas mais de um milhão de crianças na região; castigos corporais nos lares, explicitamente proibido por lei em apenas 16 países da região; violência nas escolas, onde ocorrem diferentes formas de tratamento humilhante e bullying, apesar de proibição legal; e preocupações acerca do abuso e exploração de crianças na comunidade, inclusive falta de salvaguardas em atividades de lazer, por exemplo, clubes de jovens e esportivos. O acompanhamento da consulta em nível regional incluirá negociações relativas ao comprometimento intergovernamental com a violência contra as crianças e o fortalecimento de importantes parcerias. Por exemplo, o Conselho da Europa, que co-organizou a consulta, está implementando um novo programa sobre a violência contra as crianças. A participação das crianças também será mais fortalecida através de atividades de redes de ONGs, principalmente da Save the Children, e tentará incluir as crianças mais sistematicamente no diálogo político. A consulta foi imediatamente seguida de uma revisão regional dos compromissos assumidos pelos países da Europa e Ásia Central no $2^{\circ}$ Congresso Mundial Contra a Exploração Sexual Infantil, realizado em Yokohama, Japão, em 2001, enfatizando assim os elos do estudo com a ação acelerada contra a exploração sexual e tráfico infantil.

Na sessão final em Joanesburgo, África do Sul, foi proposta a convocação de uma consulta de toda a África sob os auspícios da União Africana, que resultaria em uma "declaração da União Africana" sobre a violência contra as crianças. Essa declaração unificaria o resultado do processo consultativo do leste e sul da África com as duas outras consultas regionais realizadas na África. No fórum mais amplo da consulta, foram discutidas muitas outras questões, tais como a discriminação, HIV/Aids e práticas tradicionais (como casamento precoce, mutilação/ extirpação genital feminina), os desafios do pós-conflito e a importância de harmonizar as leis dos costumes e as leis civis. Foram discutidas as formas particulares pelas quais as meninas são especialmente alvejadas e vitimizadas, inclusive os elos com a violência doméstica. Esse tema será abordado na 2a Conferência Política Internacional sobre a Criança Africana, organizada pelo Fórum Político da Criança Africana em colaboração com a União Africana, Unicef e Plan International, em maio de 2006. Além disso, houve uma proposta de que o tema para o Dia da Criança Africana em 2006 seja "Violência contra as crianças".

A consulta caribenha teve como facilitador o Mercado Comum e Comunidade do Caribe (Cari- 
com). Vários países da região iniciaram ações de acompanhamento. Por exemplo, na Jamaica, foi criada a Aliança para a Prevenção da Violência, uma organização guarda-chuva que reúne grupos e agências que trabalham com a prevenção da violência, encabeçada pelo ministro da Saúde.

A Comissão Interamericana de Direitos Humanos co-organizou a consulta da América Latina, que produziu uma declaração assinada por participantes de alto nível. A declaração destacou a necessidade de ação para controlar a violência de gangues e a necessidade de soluções sustentáveis, baseadas na comunidade, para abordar a violência contra as crianças, respeitando seus direitos e permitindo-lhes compreender tais direitos. Anteci-padamente a essa consulta, foi criado pela Comissão Econômica para a América Latina e o Caribe um fórum virtual para solicitar opiniões do público em geral sobre a violência contra as crianças. As quase 300 respostas recebidas foram repassadas ao especialista independente e aos participantes da consulta.

A participação das crianças foi um elemento importante de cada consulta regional, e uma série dessas compreendeu eventos específicos com o envolvimento das crianças. As crianças e adolescentes participaram de reuniões preparatórias a cada uma das consultas regionais, fornecendo-lhes assim uma oportunidade de explorar com seus pares as questões relativas à violência e delinear a natureza da sua participação nas consultas. A participação das crianças foi facilitada pela Save the Children Alliance com o apoio de parceiros e as crianças foram selecionadas de acordo com um conjunto de critérios especialmente desenvolvidos, corroborados por protocolos específicos, levandose em conta a idade e a maturidade.

Mais de 260 crianças tiveram participação direta nas consultas e no estudo; 29 crianças compareceram à Consulta do Caribe; 25, no sul da Ásia; 25, na África Ocidental e Central; 22, na América do Norte; 30, na América Latina; 26, no leste da Ásia e Pacífico; 27, no Oriente Médio e Norte da África; 24, na Europa e Ásia Central; e 55, no leste e sul da África. As crianças que participaram das consultas representaram redes de crianças de países da região. As crianças e adolescentes adotaram sua própria declaração ou documento final em cada consulta regional, identificando como prioridades: 1) a consulta com crianças na formulação de leis e políticas sociais, com ênfase universal na necessidade de banir o castigo corporal; 2) a implementação e vigência de leis severas contra a violência; 3 ) maior alocação de recursos para crianças; 4) o apoio fortalecido de iniciativas infantis; 5) a conscientização entre adultos e crianças acerca dos direitos infantis, do impacto da violência contra as crianças e formas alternativas de disciplina; e 6) a necessidade de criar ouvidorias para as crianças onde não existam tais instituições. As recomendações e apresentações pelas crianças e adolescentes contribuíram diretamente para as discussões do grupo de trabalho nas consultas e estão refletidas nas recomendações finais das consultas.

As consultas com as crianças antes das consultas regionais foram realizadas em 17 países da América Latina, representando mais de 2.200 crianças; em seis países do leste e sul da África e no Canadá e nos Estados Unidos. Uma série de grupos focais com crianças e jovens na América do Norte também destacou preocupações comuns nas regiões, conclamando a uma proibição total do castigo corporal, e identificou o desafio da discriminação com base no sexo, raça e outros, solicitando o acesso à educação de qualidade e melhores serviços para retirar as crianças e os adolescentes de situações de vulnerabilidade.

A mídia participou de cada consulta regional e também desempenhou um papel de defensor na promoção das questões. Em todas as regiões, foi enfatizado o papel da mídia para romper o silêncio em torno da violência contra as crianças e influenciar as normas sociais e as atitudes da comunidade. $\mathrm{O}$ especialista independente agradece a atenção que lhe foi conferida e também ao estudo pela mídia, e ficou contente por ter podido falar em tantos fóruns de imprensa. Na consulta da África Ocidental e Central, os jornalistas propuseram a criação de uma rede de profissionais da mídia, reconhecendo a necessidade de dar um cunho mais responsável às notícias sobre a violência contra as crianças, inclusive proteger mais as crianças, e o papel potencial da mídia no apoio de medidas para tratar da violência contra as crianças. Durante uma apresentação pelo Departamento de Proteção Infantil da Comunidade Econômica dos Estados da África Ocidental (ECOWAS), os jornalistas foram sensibilizados acerca das questões relativas às notícias sobre a violência contra as crianças e foram produzidas diretrizes para os jornalistas. Os delegados reiteraram o papel central da mídia nas recomendações que emergiram da consulta, que, entre outras coisas, demandam o rompimento da cultura do silêncio acerca da violência contra as crianças e a conscientização sobre a questão envolvendo toda a comunidade, líderes religiosos e tradicionais, a mídia, os pais e as crianças.

Também foi abordada a violência contra as crianças na mídia, inclusive o acesso à pornografia e material ofensivo, principalmente na internet e na 
florescente indústria de telefonia móvel. Em muitos casos, ficou claro que as crianças e os adolescentes eram muito mais avançados do que os adultos no que tange ao conhecimento das questões e também às formas de resposta. Na consulta do leste da Ásia e Pacífico, um encontro temático de especialistas foi organizado pela End Child Prostitution, Child Pornography and Trafficking of Children for Sexual Purposes (ECPAT - Pelo Fim da Prostituição, da Pornografia Infantil e do Tráfico de Crianças com Propósitos Sexuais) para discutir a influência da mídia na violência contra as crianças e oferecer informações aos desdobramentos da consulta. Na consulta do Oriente Médio e da África do Norte, os parceiros do setor privado foram convidados como facilitadores das discussões com os delegados da consulta sobre o escopo do problema e também sobre o que poderia ser feito.

\section{Análise das observações finais do Comitê sobre os Direitos da Criança}

O especialista independente continuou em contato com o Comitê sobre os Direitos da Criança, o corpo de tratado de 18 membros que monitora a Convenção sobre os Direitos da Criança, que iniciou a preparação do estudo através de uma recomendação à Assembléia Geral. Os membros atuais e pregressos do Comitê participaram das consultas regionais e de outros encontros relacionados ao estudo e, tendo-se em mente o fato de que o Comitê considerou a questão da violência contra as crianças na sua análise dos relatórios dos Estados integrantes da Convenção, o especialista independente realizou uma análise das observações finais do Comitê sobre o assunto.

Essa análise indicou que os principais pontos de preocupação levantados pelo Comitê incluem os insuficientes recursos financeiros e humanos alocados, bem como programas inadequados estabelecidos para prevenir e combater a violência contra as crianças. As crianças não têm mecanismos adequados para registrar queixas e, em muitos casos, há obstáculos ao processo contra abuso e negligência infantil. Há carência de medidas de reabilitação para as crianças vítimas de maus-tratos e abuso, bem como de informações e dados abrangentes sobre as diferentes manifestações de violência contra as crianças, levando a uma consciência limitada dos maus-tratos e abuso infantis. O Comitê expressou a preocupação de que o castigo corporal ainda seja amplamente aceito e praticado na família e que um número limitado de países tenha proibido o castigo corporal no lar e na família, enquanto que em alguns países medidas legislativas prevejam tal castigo. A violência contra as mulheres na família permanece disseminada e continua a ter um impacto negativo nas crianças, e o Comitê expressou a preocupação de que a violência doméstica contra as mulheres possa estar associada ao abuso infantil no âmbito familiar.

O Comitê tem chamado a atenção para leis ultrapassadas referentes ao abuso sexual e também tem constatado informações confusas sobre o predomínio de abuso e negligência infantil, observando que o baixo número de casos notificados talvez possa ser um indício de um sistema de notificação ineficaz ou resultado de atitudes tradicionais, que impedem a notificação. O Comitê observou que as leis domésticas relativas ao abuso sexual são muitas vezes ultrapassadas e às vezes não há uma legislação que proíba claramente o abuso e a exploração sexual infantil. Talvez também não exista uma legislação que defina claramente o consentimento em questões sexuais e há procedimentos insuficientes para processar os perpetradores, de forma que pouquíssimos casos de abuso físico e sexual são efetivamente acompanhados pela polícia ou levados ao tribunal. A estigmatização social das vítimas de abuso sexual, bem como a falta de programas de recuperação social e psicológica e as limitadas possibilidades de as vítimas serem reintegradas à sociedade também atraíram a preocupação do Comitê.

O Comitê observou que o castigo corporal ainda é amplamente praticado nas escolas, muitas vezes não é explicitamente proibido pela legislação doméstica e é, às vezes, sustentado pela legislação, considerada pelo Comitê em contravenção com o artigo 19 da Convenção. O Comitê tem declarado que há normalmente uma conexão entre a aceitabilidade social e legal do castigo corporal e altos níveis de abuso infantil e que a tolerância do castigo corporal nas escolas dificulta educar os pais acerca de formas alternativas de disciplina. O Comitê também expressou sua preocupação com relação ao uso de castigo corporal em instituições públicas e em contextos de cuidado alternativo, inclusive orfanatos e centros de reabilitação, e a colocação de crianças em necessidade de cuidado alternativo, em especial os meninos, em instituições para infratores juvenis, bem como a incidência de abuso sexual e outras formas de abuso nos lares infantis. Nesse contexto, o Comitê tem expresso preocupação especial no que concerne à legislação doméstica que dá aos pais o direito de recorrer ao cuidado institucional quando os filhos são considerados fora de controle e a vulnerabilidade dessas crianças à violência.

O Comitê observou a ocorrência de violência 
contra as crianças na administração da justiça juvenil, enfatizando que as crianças são vítimas de tratamento ou castigo cruel, desumano ou degradante, levado a cabo especialmente pelas mãos de policiais em delegacias, locais de detenção e prisões. A idade mínima de responsabilidade criminal é muitas vezes muito baixa. Em muitos países, as pessoas que cometeram crimes com menos de 18 anos podem ser sentenciadas à morte ou à prisão perpétua ou sujeitas a castigo corporal ou outros, inclusive amputação, chibatadas ou apedrejamento. $\mathrm{O}$ período de investigação e detenção pré-julgamento pode ser prolongado e as pessoas com menos de 18 anos nem sempre podem ser separadas dos adultos. As condições de detenção de crianças em delegacias ou centros de detenção são precárias, podendo chegar ao tratamento cruel, desumano ou degradante. Os métodos usados pelas autoridades da lei podem em alguns casos pôr em risco a vida das crianças. Geralmente, há falta de dados estatísticos sobre a administração de justiça juvenil, um número e uso limitados de tribunais e juízes juvenis especializados, supervisão, monitoramento e treinamento da equipe de má qualidade e ausência de mecanismos de queixa eficazes, acessíveis às crianças e independentes para os jovens detentos. As medidas de recuperação e a reintegração social são freqüentemente ausentes.

O Comitê expressou sua preocupação com relação ao crescente envolvimento das crianças na indústria do sexo, inclusive prostituição e pornografia, o tema do Protocolo Opcional para a venda, prostituição e pornografia infantis da Convenção sobre os Direitos da Criança, vigente em 2000, e o tráfico infantil em grande escala, em especial de meninas, com objetivo de exploração sexual e outras formas de exploração. O Comitê expressou sua preocupação de que as crianças sexualmente exploradas sejam criminalizadas em alguns países, e há uma falta de legislação específica que proíba o tráfico de seres humanos, inclusive para os propósitos de prostituição.

O número crescente de crianças de rua, a maioria vivendo em condições extremamente difíceis, e a vulnerabilidade dessas crianças à violência, tortura, abuso sexual, exploração, assassinato e abdução também atraíram a preocupação do Comitê. Foi observada a falta de uma estratégia sistemática e abrangente que trate da situação e proteja essas crianças. Da mesma forma, o Comitê identificou a exploração econômica das crianças como um fator que pode aumentar sua vulnerabilidade à violência. Observou-se que, apesar da ampla ratificação da Convenção no 182 da Organização Internacional do Trabalho referente à Interdição das Piores Formas de Trabalho das Crianças e à Ação Imediata com vista à sua Eliminação e da adoção por alguns países de leis mais rigorosas com relação ao trabalho infantil, uma alta porcentagem de trabalhadores infantis participam de atividades que representam um risco a sua saúde e desenvolvimento, sendo que alguns trabalham em condições perigosas e/ou abusivas. O Comitê expressou a sua preocupação com relação à falta de salvaguardas legais que protejam as crianças empregadas no setor informal, inclusive em empresas pequenas e familiares, deixando-as vulneráveis ao abuso, inclusive sexual.

A persistência de práticas tradicionais nocivas, inclusive a mutilação genital feminina, casamentos forçados e/ou precoces, violência relacionada a questões de dotes, infanticídio e escravização femininos e tabus alimentares, foi destacada pelo Comitê, que nutre preocupação com relação à falta de intervenções para tratar dessas questões. Chamou atenção ao impacto de idades legais mínimas diferenciais para o casamento para meninos e meninas, considerado discriminatório pelo Comitê, o que facilita a prática do casamento precoce. Também sublinhou o problema dos assassinatos por honra, que afetam as crianças diretamente, bem como indiretamente, quando envolvem suas mães e outros parentes do sexo feminino, e observou que a polícia muitas vezes reluta em prender os perpetradores ou, onde são presos e processados, estes recebem punição leniente ou proforma.

O Comitê ressaltou as condições subjacentes que exacerbam a vulnerabilidade das crianças à violência. Dentre elas, a pobreza, padrões, procedimentos e políticas inadequados para garantir e proteger os direitos de crianças internamente desalojadas, refugiadas, que buscam asilo e desacompanhadas, inclusive o seu acesso à educação, saúde e outros serviços sociais adequados, e os sofrimentos físicos e psicológicos resultantes de conflitos armados que afetam as crianças. O Comitê também observou a crescente vulnerabilidade das crianças com HIV/Aids e das crianças órfãs como resultado da pandemia de violência. Também chamou a atenção para os riscos especiais das crianças com deficiências, principalmente em instituições ou em cuidado residencial, com respeito à violência e a maior vulnerabilidade das crianças pertencentes às minorias e grupos raciais à discriminação e violência. Nesse contexto, o Comitê observa que talvez faltem medidas legais que proíbam o incitamento à discriminação racial e violência racialmente motivada. A polícia e os promotores talvez não consigam investigar atos de violência racialmente motivada 
com rapidez e eficácia e podem relutar em identificar um motivo racial como tendo instigado tal violência. O Comitê também observou que, em alguns países, há poucas acusações e sentenças com relação ao número de incidentes notificados e que os perpetradores às vezes recebem sentenças leves.

\section{Conclusão}

Através das consultas regionais, sub-regionais e nacionais, encontros com especialistas, visitas de campo e análise do trabalho de mecanismos de direitos humanos, em especial do Comitê sobre os Direitos da Criança, o especialista independente identificou uma série de áreas-chave, principalmente no que tange à prevenção e resposta eficaz à violência contra as crianças, que serão o foco do seu trabalho no próximo ano. Dentre elas, a contínua legalidade e predomínio do castigo corporal contra crianças nos lares, escolas, cuidado alternativo, instituições e no sistema de justiça juvenil; a vulnerabilidade das crianças em conflito com a lei, bem como das crianças de rua, à violência; e a difusão de práticas tradicionais nocivas. Ele também ficou bem consciente das condições subjacentes, como atitudes da comunidade com relação à violência, discriminação, pobreza, o status desigual das mulheres e meninas, a falta de acesso à educação de qualidade e a negação dos direitos humanos em geral, que exacerbam a vulnerabilidade das crianças à violência. Também foram evidenciadas a falta de dados sistemáticos e de qualidade e a importância da capacitação dos que trabalham com as crianças.

Ao concluir seu relatório final para o secretáriogeral, bem como outros textos relacionados, o especialista independente usará como base as informações que emergiram das consultas, visitas de campo, encontros com especialistas e outros eventos. Ele dará peso significativo ao resultado da análise das respostas ao questionário enviado aos governos e outras submissões e se concentrará no desenvolvimento de respostas abrangentes, multifacetadas e interdisciplinares à violência contra as crianças e estratégias para erradicá-la.

\section{Agradecimentos}

O apoio para o Estudo sobre Violência contra as Crianças foi dado pelos governos, organismos regionais, intergovernamentais e não-governamentais, bem como entidades das Nações Unidas, principalmente pelo Escritório do Alto Comissariado da ONU para Direitos Humanos (OHCHR), o Fundo das Nações Unidas para a Infância (Unicef) e a Organização Mundial da Saúde (OMS). Há outras experiências e contribuições oferecidas por uma gama de parceiros das Nações Unidas. Por exemplo, a Organização Internacional do Trabalho (OIT), o Escritório do Alto Comissariado da ONU para Refugiados (UNHCR), a Organização das Nações Unidas para a Educação, a Ciência e a Cultura (Unesco).
O especialista independente também discutiu a colaboração com a Divisão para o Avanço das Mulheres e o Departamento de Assuntos Econômicos e Sociais do Secretariado; organizações não-governamentais nacionais, regionais e internacionais, principalmente as fornecidas pelo subgrupo sobre crianças e violência criado dentro do Grupo de ONGs para a Convenção sobre os Direitos da Criança e o Painel Consultor de ONGs para o estudo. A Save the Children continua apoiando a participação das crianças no estudo.

Artigo apresentado em 4/03/2006 Artigo aprovado em 17/03/2006 Versão final apresentada em 17/03/2006 